\title{
Seasonal Home Advantage in English Professional Football; 1974-2018
}

\author{
Thomas Peeters ${ }^{1,3}$. Jan C. van Ours ${ }^{2,3,4,5}$
}

(c) The Author(s) 2020

\begin{abstract}
We study seasonal home advantage in English professional football over the period 1974 to 2018. We distinguish between absolute home advantage, enjoyed equally by all teams in a division, and relative home advantage, which differs among teams in the division. We find that absolute home advantage is substantial, ranging from 0.59 to 0.64 in terms of points per game or 0.44 to 0.46 in terms of goal difference. Likewise, clubs differ substantially in the relative home advantage they enjoy. Relative home advantage is positively related to within-team variation in attendance and the use of an artificial pitch. Despite big cross-divisional differences in attendance, absolute home advantage is about the same in all divisions. Finally, there is a substantial decline in absolute home advantage over time that materializes equally across divisions.
\end{abstract}

Keywords Professional football $\cdot$ Home advantage $\cdot$ Attendance $\cdot$ Managers

JEL Classification Z21 · L83

The authors thank Martin van Tuijl, Alex Krumer, Stijn Baert, one of the editors of the special issue and an anonymous referee for comments on an earlier version of this paper.

Thomas Peeters

peeters@ese.eur.nl

Jan C. van Ours

vanours@ese.eur.nl

1 Erasmus School of Economics, Erasmus Center for Applied Sports Economics (ECASE),

Erasmus Research Institute for Management (ERIM), Erasmus University Rotterdam,

Rotterdam, The Netherlands

2 Tinbergen Institute Amsterdam, Amsterdam, The Netherlands

3 Tinbergen Institute Rotterdam, Rotterdam, The Netherlands

4 Department of Economics, University of Melbourne, Parkville, Australia

5 CEPR, London, UK 


\section{Introduction}

The existence of home advantage in professional football is well-established. Pollard (1986) studies how home advantage has developed in the top English division since its inception in 1888 . He concludes that up to 1984 home advantage has been remarkably stable and that it is less marked in local derbies and the FA cup. Furthermore, Pollard (1986) concludes that crowd size and travel fatigue are not important while the effects of familiarity with local conditions, referee bias, and team tactics are unclear. Following Pollard (1986), quite a few studies have investigated home advantage in English professional football. Barnett and Hilditch (1993) investigated the effects of playing on an artificial pitch rather than on natural grass. They find an additional home advantage of playing on an artificial pitch of 0.28 points and 0.31 goals per match. ${ }^{1}$ Clarke and Norman (1995) study seasonal home advantage for all English football teams over the period 1981 to 1990 . Their study shows a lot of variation between teams and over time. Bray et al. (2003) study teams from all four divisions of the English football league over 19 seasons (1981 to 2000) finding that teams on average won $22 \%$ more games at home than away. Carmichael and Thomas (2005) suggest that home advantage is related to difference in playing style in the sense that home teams play more aggressively while away teams play more defensively. Dawson et al. (2007) conclude that in the English Premier League underdogs are more likely to receive disciplinary sanctions than favorites. They also state that due to a home team bias, home teams play more aggressively in front of large crowds but do not receive more disciplinary sanctions. Nevertheless, Johnston (2008) did not find evidence for a referee bias affecting the home advantage. However, Boyko et al. (2010) claim that home advantage in English Premiership football is influenced by crowd size and referee decisions about penalties and yellow cards. Buraimo et al. (2010) conclude that there is a referee bias favoring home teams. Allen and Jones (2014), studying Premier League matches, conclude that from season 1992/93 to season 2011/12 average home advantage did not show an upward or downward trend. Furthermore, they find teams at the lower end of the league table had a greater home advantage while contrary to what Attrill et al. (2008) find, it did not matter whether teams play in a red colored or different colored shirt.

Home advantage in professional football is also studied in other countries and in international competitions and tournaments. For example, Buraimo et al. (2010) look at the Bundesliga, the highest division in Germany, and Armatas and Pollard (2014) at the Superleague in Greece. Garicano et al. (2005) show that Spanish referees grant more extra playing time when the home team is narrowly behind in the score. Pollard and Armatas (2017) study the home advantage in the group stages of the qualification for World Cup finals finding that this was greatest in Africa and South America and lowest in Europe. Ponzo and Scoppa (2018) analyze

\footnotetext{
1 There were four clubs in English professional football that had an artificial pitch for a while mainly during the 1980s. In 1995 such pitches were banned but since 2016 they are permitted in lowest two divisions in English professional football.
} 
same-stadium derbies across Europe, i.e. matches between teams that share the same stadium. This set-up rules out travel distance and familiarity with the stadium as determinants of the home advantage. The main conclusion is that home advantage depends on the support of the crowd because referee decisions tend to be biased in favor of the home team. Krumer and Lechner (2018) find that in the German Bundesliga clubs lose the home advantage they enjoy in the weekend, when they play midweek. This is attributed to a smaller stadium crowd and the psychological effect that players consider midweek matches less relevant. In line with this, Goller and Krumer (2020) conclude that in the top German, Spanish, French, and English football leagues home advantage is affected by the day of play. Non-frequently played days also have a lower attendance than frequently played days. Along the same lines, Krumer (2020) finds that kick-off times matter for home advantage in the group stage games of the UEFA Europa League because they affect the size of the stadium crowd. For Dutch professional football, van Ours (2019) finds a home advantage of 0.33 points and 0.42 goals per match while teams who play on an artificial pitch have an additional home advantage. In a recent study Van Damme and Baert (2019) investigate the effects of various distance measures on home advantage in European international football concluding that altitude is important as well as crowd sizes. Amez et al. (2020) find that the second leg of a knock-out confrontation does not have a bigger home advantage, which matters because clubs play two matches against each other in the knock-out phase of the UEFA Europa League and UEFA Champions League.

Despite these studies, it is not entirely clear how important each of the relevant determinants of home advantage is and, consequently, whether and why some clubs enjoy a relatively stronger home advantage. Indeed, one may wonder why home advantage is an issue at all in a double round-robin competition. If every team plays the same number of matches home and away against the same opponents, home advantages cancel out. Therefore home advantage is only a relevant concern for the fairness of this competition format, if some teams have a persistently larger home advantage than others.

In our paper we therefore ask whether seasonal home advantage is a relevant concern from a competitive point of view. If the home advantage is equally distributed over the teams in a competition, it cancels out at the end of the season. On the other hand, if some teams have a larger home advantage than others this may introduce an element of unfair competition. Whether an unequal distribution of home advantages can be mitigated depends on the origin of the advantage. If, for example, the size of the home crowd increases home advantage, there is not much the league organizer can do about the inequality in home advantage. However, if home advantage is related to the nature of the pitch — artificial or natural grass - certain types of pitches may be banned to level the playing field.

We calculate team-specific seasonal home advantage for all clubs in the four English professional football divisions over a time period of 45 years from 1974 
to $2018 .^{2}$ Focusing on seasonal home advantage rather than home advantage in individual matches allows us to separate home advantage from season-specific differences in team quality. In turn, we can then investigate systematic differences in home advantage among teams in the league. In our baseline analysis, we focus on seasonal home advantage of a team in a particular season relative to the league average home advantage in that season. Our results indicate that this difference in home advantage among teams is substantial. Hence, relative home advantage does lead to a competitive advantage for some teams.

As in previous studies we investigate the effect of stadium attendance on home advantage, but we also look at the nature of the pitch (natural grass or artificial), whether a team was recently promoted or relegated and whether wages paid to players matter. Both attendance and the nature of the pitch correlate strongly with the relative home advantage of a team, but, taken together, our variables explain only a small proportion of the variance in relative home advantage among teams. When we look at the managers (coaches) the teams employed, we also find stark differences in the average relative home advantage individual managers enjoyed. Again, these individual differences cannot be easily explained using the personal charateristics of the managers.

In addition to differences in relative home advantage between clubs, we also examine the development of the absolute home advantage over time. We find that home advantage in all leagues has declined significantly over the period of analysis. We made an attempt to find an explanation for this secular decline in home advantage in English professional football but did not succeed. We can only speculate about potential determinants of the secular decline that manifested itself in all four leagues and that is what we do.

\section{Calculating Seasonal Home Advantage}

Clarke and Norman (1995) present a simple method to disentangle the performance of a team in a particular season into the quality of a team and its home advantage. In terms of points difference, this works as follows. Ignoring random influences and ignoring for the moment an index for season, at the end of the season the home point difference $(H P D)$ of team $i$ depends on the quality $q_{i}$ of the team, the quality of its opponents $q_{j}$ and the home advantage of the team $h_{i} \cdot{ }^{3}$

\footnotetext{
2 The names of the four divisions have changed over the period of analysis. We use the current names. We refer to years instead of seasons. Our data are from season 1973/74 to 2017/18.

3 We also ignore the discrete character of the point difference. For individual matches the HPD can only have three values: $+3,0,-3$. However, since a season varies from 38 to 46 matches this discrete character is not that relevant. Note that Home Win Difference can have values of $+1,0,-1$. Therefore, since Home Win Difference and Home Point Difference are perfectly correlated we ignore Home Win Difference focusing on Home Point Difference and Home Goal Difference.
} 


$$
H P D_{i}=(N-1) q_{i}-\sum_{j(j \neq i)}^{N} q_{j}+(N-1) h_{i}
$$

where $N$ is the number of teams in the league. Therefore, team $i$ has $N-1$ home matches. Similarly the away point difference (APD) of team $i$ is equal to:

$$
A P D_{i}=(N-1) q_{i}-\sum_{j(j \neq i)}^{N} q_{j}-\sum_{j(j \neq i)}^{N} h_{j}
$$

Quality is normalized such that average quality over the teams in a league is zero: $\sum_{i=1}^{N} q_{i}=0$. Furthermore, $H$ is defined as the total home advantage aggregated over all teams: $H=\sum_{i=1}^{N} h_{i}=N \bar{h}$ where $\bar{h}$ is the average home advantage over all teams in the league. Therefore:

$$
\sum_{j(j \neq i)}^{N} q_{j}=-q_{i} \text { and } \sum_{j(j \neq i)}^{N} h_{j}=N \bar{h}-h_{i}
$$

Using equations (3) we can rewrite equations (1) and (2) as:

$$
H P D_{i}=N q_{i}+(N-1) h_{i} \text { and } A P D_{i}=N q_{i}+h_{i}-N \bar{h}
$$

From this it is easy to find for the home advantage and the quality of team $i$ :

$$
h_{i}=\frac{H P D_{i}-A P D_{i}-H}{N-2} \text { and } q_{i}=\frac{H P D_{i}-(N-1) h_{i}}{N}
$$

Using end of season league tables we can calculate the quality and home advantage for every team in the league. Average seasonal performance of team $i$ is equal to:

$$
P_{i}=\frac{H P D_{i}+A P D_{i}}{2 N}=q_{i}+\frac{\left(h_{i}-\bar{h}\right)}{2}
$$

Clearly, performance has two components, quality and relative home advantage. ${ }^{4}$ If $h_{i}>\bar{h}$, performance is enhanced by superior home advantage but if home advantage of team $i$ is equal to the average home advantage, performance only depends on quality. Obviously, in the performance measure the relative home advantage counts for half the matches. In the empirical analysis, we will use relative home advantage as our main dependent variable.

As an alternative to home point difference and away point difference we also use home goal difference (HGD) and away goal difference (AGD). This leads to home advantage in terms of goal difference which is strongly but not perfectly correlated with home advantage in point difference. While the home advantage in terms of points is important from a competitive point of view, the home advantage in terms

\footnotetext{
${ }^{4}$ Note that in this set-up the average performance over all teams in a league in a particular season is normalized to zero, i.e. $\sum_{i}^{N} P_{i}=0$.
} 


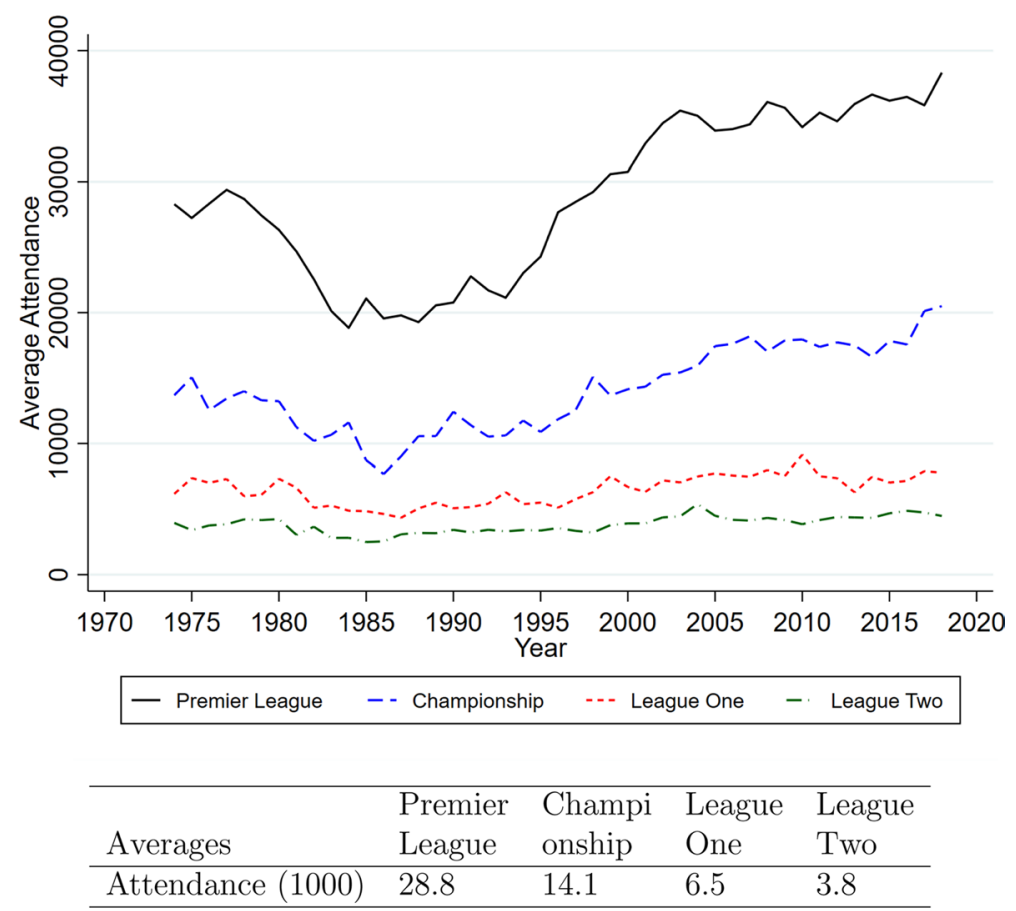

Fig. 1 Attendance by division; 1974-2018

of goal difference is indicative of a difference in playing style of home and away matches.

\section{Descriptive Data Analysis}

\subsection{Developments Over Time}

In the appendix we provide detailed information about the data we collected for the 45 seasons of professional English football. Figure 1 shows the evolution of match attendance in the English professional football leagues. As shown in the table at the bottom of the graph there are substantial differences between the leagues. Whereas the average Premier League match had a crowd of almost 30,000, the Championship had almost 15,000, League One a little over 5000 and in League Two less than 4000 spectators visited a match.

The developments over the period of analysis are spectacular. We see a big drop in average attendance from 1974 through the mid-1980s. After that, we observe a steady increase, which runs all the way to 2018. In absolute terms, this evolution is most dramatic for Premier League clubs, but there was a big relative increase at all levels. In the Premier League the average crowd size increased from about 20,000 in the mid 1980s to almost 40,000 recently; in the Championship the increase was from less than 8000 
Premier League

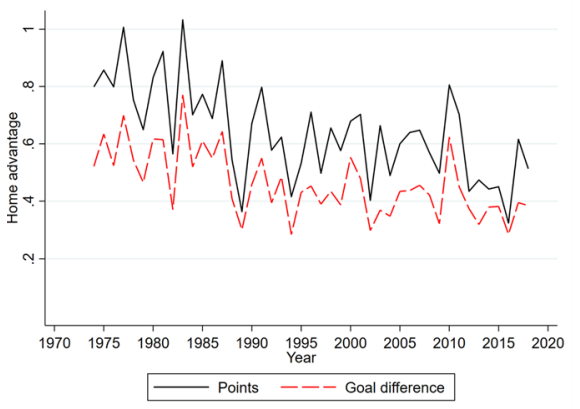

League One

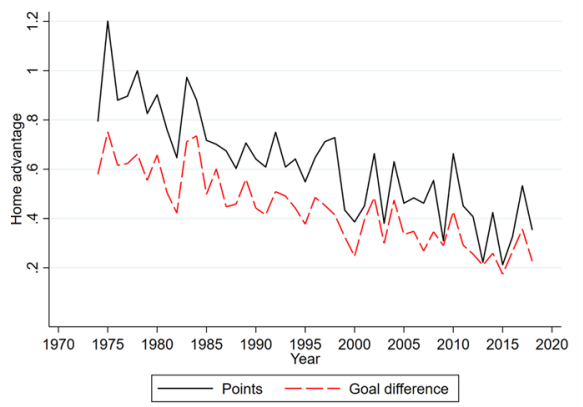

Championship

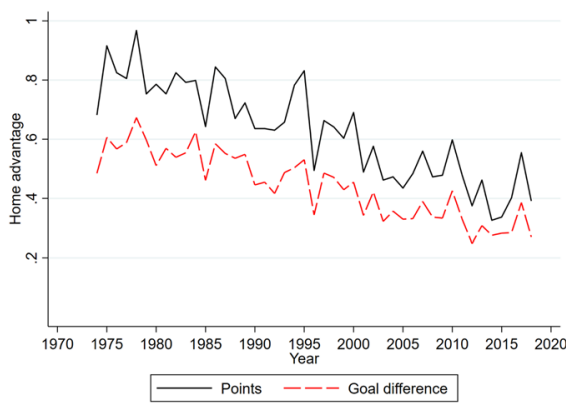

League Two

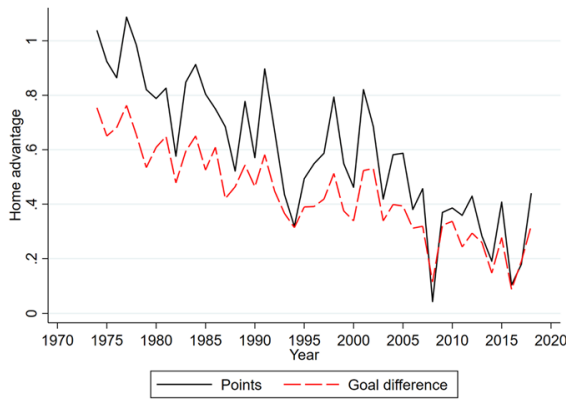

\begin{tabular}{lllll}
\hline $\begin{array}{l}\text { Average Home } \\
\text { Advantage }\end{array}$ & $\begin{array}{l}\text { Premier } \\
\text { League }\end{array}$ & $\begin{array}{l}\text { Champi } \\
\text { onship }\end{array}$ & $\begin{array}{l}\text { League } \\
\text { One }\end{array}$ & $\begin{array}{l}\text { League } \\
\text { Two }\end{array}$ \\
\hline Points & 0.64 & 0.63 & 0.62 & 0.59 \\
Goal Difference & 0.46 & 0.44 & 0.44 & 0.44 \\
\hline
\end{tabular}

Fig. 2 Absolute home advantages English professional football by league; 1974-2018

to over 20,000; in League One from less than 5000 to almost 8000 and in League Two from 2500 to about 4500 .

Based on the calculations presented in the previous section, Fig. 2 shows the evolution of the absolute home advantage by league. As presented in the table at the bottom of the figure, average home advantage is highest in the Premier League and lowest in League Two although the differences are small. Whereas home advantage in the Premier League is 0.64 points and 0.46 goals, for League Two this is 0.59 points and 0.44 goals. The graphs in Fig. 2 show that on average there is a clear positive home advantage but there are substantial fluctuations from year to year. In the Premier League for example, home advantage fluctuates between 0.4 and 0.9 points and between 0.3 and 0.6 goals. Still, it is clear that home advantages declines over time in all leagues.

\subsection{Individual Clubs and Home Advantage}

In terms of the on-field competition absolute home advantage is not very important, because the round robin format cancels out the aggregate effect of home advantage 
across clubs. What matters is relative home advantage, i.e. whether a club has a higher home advantage than its direct competitors.

Table 1 gives an overview of the 65 clubs, which appeared in one of the top four divisions of English football in every season over the period 1974-2018. The table shows how many years the club played in each division. There are only 3 clubs that have played in the Premier League all the time: Arsenal, Everton and Liverpool. All other clubs have played in at least two divisions, some clubs even in all four. For example, Bolton Wanderers played 15 seasons in the top division, but at one point went all the way down to the fourth division. Again other clubs, e.g. Chesterfield, Northampton Town and Rochdale, never played at the top level or even at the second level, but did maintain their position in the top four divisions throughout our data sample.

Table 1 also gives information about the average home advantage both in number of points as well as in goal difference. Over the 45 years of our period of analysis every club in the balanced panel had a positive home advantage with at the extremes Newcastle United with a home advantage of 0.99 points and 0.71 goals difference per home match, Crystal Palace with a home advantage of 0.36 points per match and Wolverhampton Wanderers with a 0.27 goals difference per home match. Naturally, these unconditional averages may be driven by a host of underlying differences between clubs, which we explore in the next section.

Figure 3 presents an overview of the spread in the two types of home advantage per club over the period of analysis. Of course, there is a high correlation between the two measures but the correlation is not perfect. Clubs with the same home advantage in number of points have a different home advantage in terms of goal difference and vice versa. What matters for the competition is the home advantage in number of points. What matters in terms of excitement during home matches is the home advantage in goal difference. Apparently, some clubs have a spectacular home play with large goal differences but enjoy the same home advantage in terms of points as clubs who play less spectacularly but secure their home matches with a small goal difference.

\subsection{Managers and Home Advantage}

In addition to looking at heterogeneity among clubs, we also investigate whether there is heterogeneity in home advantage at the level of individual managers. Unlike clubs, managers have relatively short careers in the data. Given the considerable differences in seasonal home advantage over time and division, this may distort a comparison of managerial averages in the vein of our analysis in Table 1 . Therefore we first regress seasonal home advantage on a set of season and division dummies. We then average the residual of this regression for each manager with at least six full seasons of managerial experience, taking only full seasons with a club into account. We finally normalize this number by subtracting the average level of seasonal home advantage from the manager's average. This allows us to rank managers according to the average home advantage they enjoyed over their career in the data. Any positive 


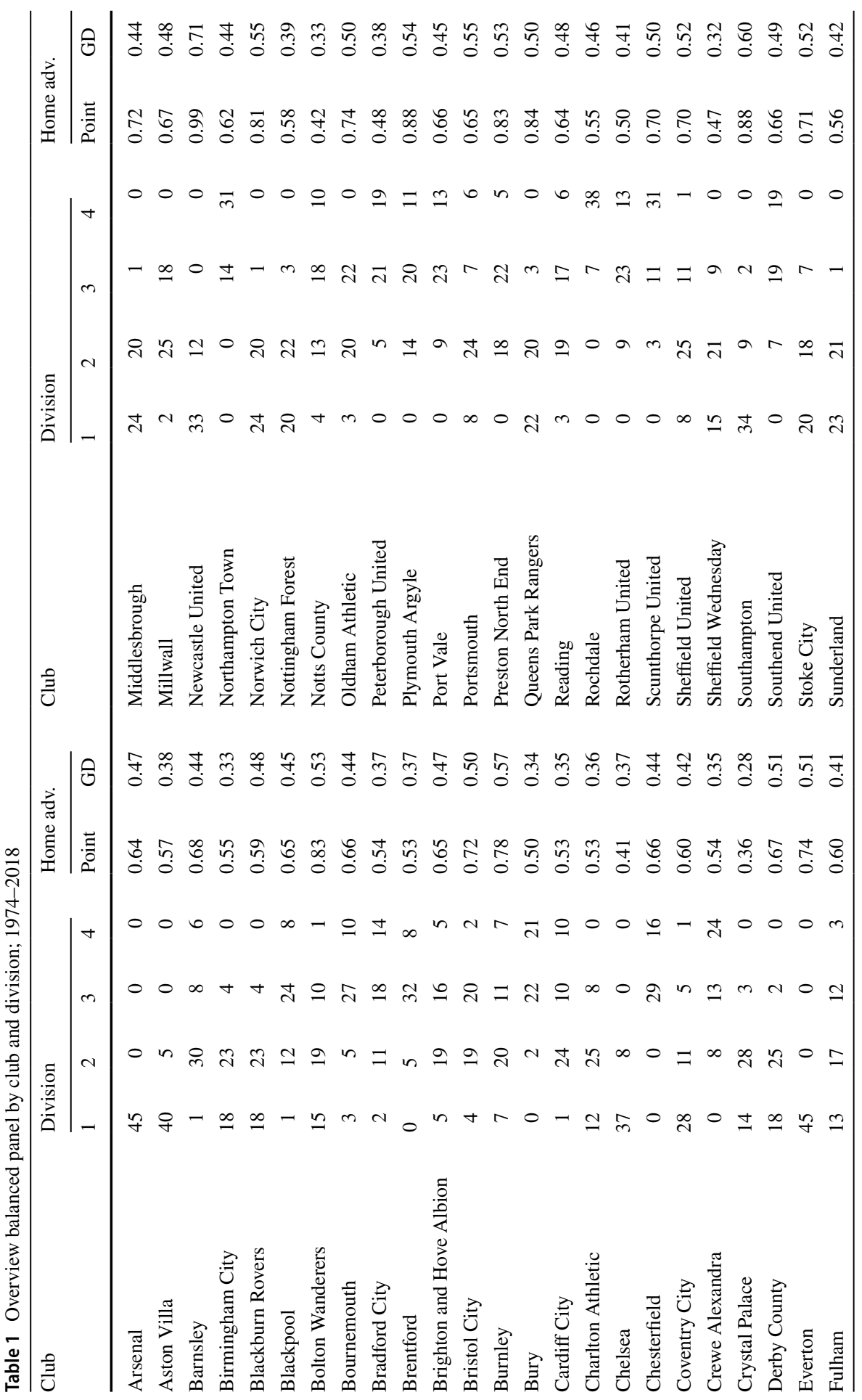




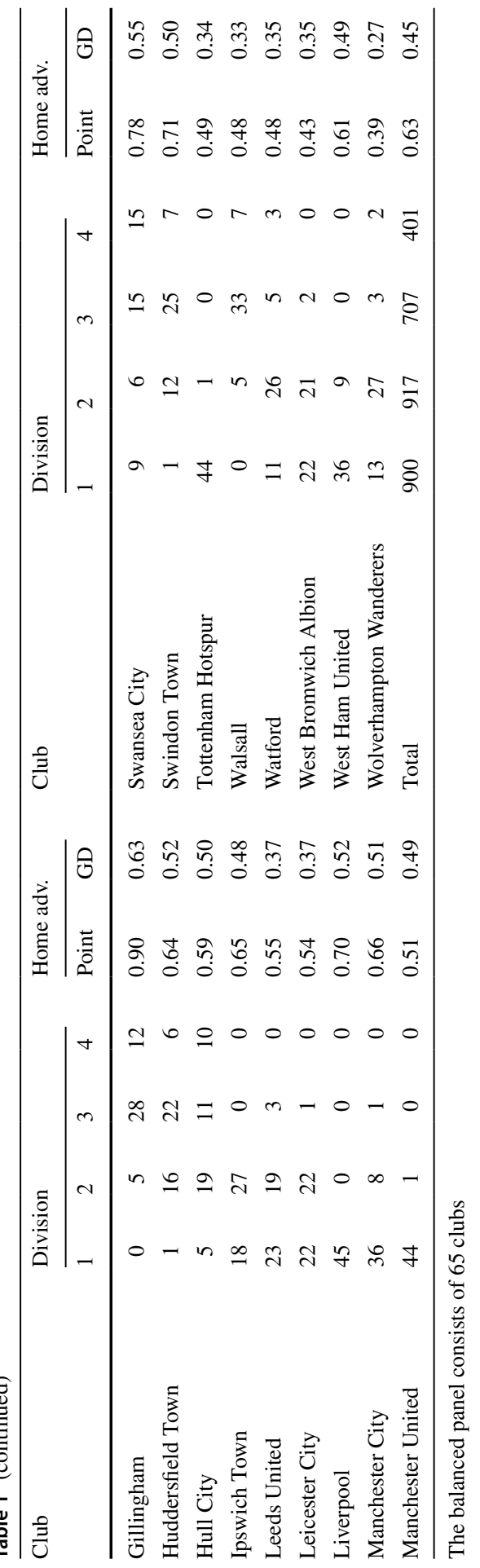

\section{글 Springer}




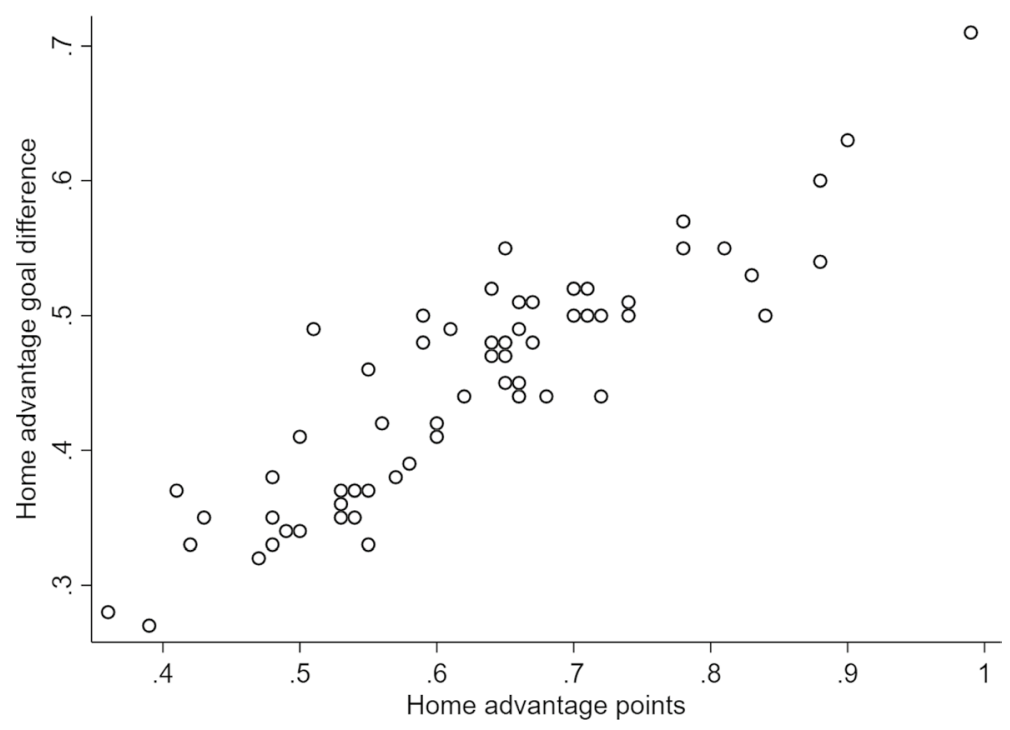

Fig. 3 Home advantage in points and goal difference balanced panel; 1974-2018

number indicates a manager enjoyed more division- and seasonally-adjusted home advantage than his peers, whereas negative numbers indicate the opposite.

Panel a of Table 2 gives the top 10 of managers ranked according to their contribution to the home advantage as measured in points. ${ }^{5}$ Clearly, many of the top 10 managers have been active in more than one league. The number one-Nigel Worthington - has been active in all leagues. David Hodgson and Jim Iley have only managed League Two teams while Harry Redknapp spent 12 seasons of his 22 as manager in the Premier League. It is also clear that home advantage in goal difference is not perfectly correlated with the home advantage in number of points. Glenn Hoddle for example ranks very high in terms of points but does not stick out in terms of goal difference.

Panel b of Table 2 gives the bottom 10 of managers ranked according to their contribution to the home advantage as measured in points. Again, there is not a clear pattern in terms of leagues in which the bottom 10 managers were active. Alan Durbin has been active in all four leagues while Jim Bentley only managed clubs in League Two and David O'Leary only managed clubs in the Premier League.

Finally, panel c of Table 2 provides information about home advantages of the most experienced managers. There is no clear pattern of a possible relationship between a manager's experience and his contribution to home advantage. For example, Dario Gradi who was a manager for 26 seasons has a small negative contribution to home advantage as measured in points. Furthermore, the former

\footnotetext{
5 Note that the ranking is based on averages. Often, the difference between the home advantages across managers may be too small to be statistically significantly different from zero, because the observations per manager tends to be low.
} 
Table 2 Contribution of managers to the home advantage

\begin{tabular}{|c|c|c|c|c|c|c|c|c|}
\hline & \multirow[t]{2}{*}{ Manager } & \multicolumn{2}{|c|}{ Home advantage } & \multicolumn{5}{|c|}{ Seasons active } \\
\hline & & Points & GD & PL & $\mathrm{Ch}$ & $\mathrm{L} 1$ & L2 & Total \\
\hline \multicolumn{9}{|c|}{ a. Top 10} \\
\hline 1 & Nigel Worthington & 0.59 & 0.28 & 1 & 4 & 2 & 1 & 8 \\
\hline 2 & Terry Cooper & 0.58 & 0.28 & 0 & 2 & 5 & 5 & 12 \\
\hline 3 & Chris Hughton & 0.58 & 0.43 & 2 & 4 & 0 & 0 & 6 \\
\hline 4 & Glenn Hoddle & 0.58 & 0.03 & 3 & 3 & 0 & 0 & 6 \\
\hline 5 & Ray Harford & 0.52 & 0.26 & 4 & 2 & 0 & 0 & 6 \\
\hline 6 & Lawrie McMenemy & 0.49 & 0.24 & 7 & 5 & 0 & 0 & 12 \\
\hline 7 & David Hodgson & 0.47 & 0.30 & 0 & 0 & 0 & 6 & 6 \\
\hline 8 & Bob Stokoe & 0.45 & 0.36 & 0 & 6 & 2 & 0 & 8 \\
\hline 9 & Harry Redknapp & 0.43 & 0.28 & 12 & 5 & 5 & 0 & 22 \\
\hline 10 & Jim Iley & 0.43 & 0.14 & 0 & 0 & 0 & 8 & 8 \\
\hline \multicolumn{9}{|c|}{ b. Bottom 10} \\
\hline 10 & David O'Leary & -0.51 & -0.30 & 6 & 0 & 0 & 0 & 6 \\
\hline 9 & Bobby Gould & -0.51 & -0.16 & 5 & 0 & 3 & 1 & 9 \\
\hline 8 & Joe Kinnear & -0.55 & -0.24 & 7 & 0 & 1 & 1 & 9 \\
\hline 7 & Jim Bentley & -0.58 & -0.41 & 0 & 0 & 0 & 7 & 7 \\
\hline 6 & Martin O’Neill & -0.58 & -0.43 & 8 & 0 & 1 & 1 & 10 \\
\hline 5 & George Petchey & -0.60 & -0.45 & 0 & 5 & 1 & 0 & 6 \\
\hline 4 & Jimmy Sirrel & -0.60 & -0.36 & 1 & 6 & 2 & 0 & 9 \\
\hline 3 & Alan Durban & -0.61 & -0.34 & 4 & 1 & 3 & 1 & 9 \\
\hline 2 & Paul Jewell & -0.64 & -0.29 & 3 & 4 & 2 & 0 & 9 \\
\hline 1 & Bobby Campbell & -0.81 & -0.43 & 1 & 5 & 1 & 0 & 7 \\
\hline \multicolumn{9}{|c|}{ c. Most experienced } \\
\hline 1 & Dario Gradi & -0.15 & -0.17 & 0 & 7 & 8 & 11 & 26 \\
\hline 2 & Alex Ferguson & -0.16 & 0.06 & 26 & 0 & 0 & 0 & 26 \\
\hline 3 & Jim Smith & 0.38 & 0.21 & 10 & 9 & 3 & 1 & 23 \\
\hline 4 & Harry Redknapp & 0.43 & 0.28 & 12 & 5 & 5 & 0 & 22 \\
\hline 5 & Graham Taylor & -0.06 & -0.03 & 9 & 6 & 3 & 4 & 22 \\
\hline 6 & Arsène Wenger & 0.16 & 0.17 & 21 & 0 & 0 & 0 & 21 \\
\hline 7 & Graham Turner & 0.05 & 0.02 & 2 & 10 & 2 & 7 & 21 \\
\hline 8 & Joe Royle & 0.14 & 0.07 & 5 & 13 & 1 & 0 & 19 \\
\hline 9 & John Lyall & -0.17 & -0.03 & 14 & 5 & 0 & 0 & 19 \\
\hline 10 & Lennie Lawrence & -0.20 & -0.10 & 5 & 8 & 6 & 0 & 19 \\
\hline
\end{tabular}

Note that the ranking of managers in panels $\mathrm{a}$ and $\mathrm{b}$ is according to their contribution to the home advantage in points; the ranking in panel $\mathrm{c}$ is according to the number of teams they managed

long-standing Manchester United manager Alex Ferguson does not appear to have a larger home advantage than the average English manager, despite the popular notion of "Fergie time". Among the 10 most experienced managers only Jim 
Smith and Harry Redknapp have a relatively large positive home advantage but all other managers are in the range from -0.2 to +0.2 .

\section{Quantitative Analysis}

\subsection{Relative Home Advantage}

To determine the drivers of home advantage at club level, we relate seasonal home advantage of club $i$ in league $j$ in season $t$ to a set of club characteristics $x$ as follows (ignoring the error term):

$$
h_{i j t}=\alpha_{i}+\beta x_{i j t}+\gamma_{j}+\delta_{t}
$$

where $x_{i t}$ is a vector of time-varying club-specific variables, $\alpha_{i}$ are club fixed effects, $\beta$ is a vector of parameters $\gamma_{j}$ are divisional dummies, and $\delta_{t}$ are season fixed effects.

In our baseline estimates, we focus on the relative home advantage by subtracting the league average home advantage thus removing the calendar year fixed effects from the analysis:

$$
h_{i j t}^{r}=h_{i j t}-\bar{h}_{j t}=\alpha_{i}+\beta x_{i j t}+\gamma_{j}
$$

In the estimation we focus on the following explanatory variables:

- Relative attendance defined as the log of the club's average home attendance divided by the division average for the season. The logic here is that higher attendance may exert pressure on the referee to favor the home team Garicano et al. (2005).

- Use of an artificial pitch which may help a club's home advantage, because visiting teams will typically not be as familiar with this type of turf as the home team is.

- Promotion of relegation to a new division since recently promoted or regulated may have an advantage if visiting teams are less familiar with their grounds compared to other grounds in the division.

- Relative wage defined as the ratio of the club's wage sum and the average wage sum in the division for the season. Richer clubs may be able to attract better players to exploit the home advantage or referees may be shy to punish more famous players.

We show parameter estimates of linear regressions but we also discuss parameter estimates for specifications which include club fixed effects to account for timeinvariant differences between clubs such as the nature and size of the pitch, the distance between the crowd and the pitch, the shape of the stadium and so on. We also include dummy variables representing the league. For clubs that always played in the same league the club fixed effects and the league dummy coincide but this is only the case for a handful of clubs. 
Table 3 Parameter estimates relative home advantage

\begin{tabular}{|c|c|c|c|c|c|c|c|c|}
\hline \multirow[t]{2}{*}{ Variables } & \multicolumn{4}{|c|}{ Relative home advantage goal difference } & \multicolumn{4}{|c|}{ Relative home advantage points } \\
\hline & (1) & (2) & (3) & (4) & $(5)$ & $(6)$ & $(7)$ & $(8)$ \\
\hline Relative attendance & $\begin{array}{l}0.05 * * \\
(0.02)\end{array}$ & $\begin{array}{l}0.08 * * \\
(0.04)\end{array}$ & $\begin{array}{l}0.07 * * \\
(0.03)\end{array}$ & $\begin{array}{l}0.07 \\
(0.05)\end{array}$ & $\begin{array}{l}0.05 \\
(0.03)\end{array}$ & $\begin{array}{l}0.12 * * \\
(0.06)\end{array}$ & $\begin{array}{l}0.09 * * \\
(0.05)\end{array}$ & $\begin{array}{l}0.07 \\
(0.08)\end{array}$ \\
\hline Artificial pitch & $\begin{array}{l}0.40 * * * \\
(0.10)\end{array}$ & $\begin{array}{l}0.35 * * * \\
(0.10)\end{array}$ & $\begin{array}{l}0.43 * * * \\
(0.10)\end{array}$ & $\begin{array}{l}0.35 * * * \\
(0.12)\end{array}$ & $\begin{array}{l}0.66 * * * \\
(0.12)\end{array}$ & $\begin{array}{l}0.54 * * * \\
(0.17)\end{array}$ & $\begin{array}{l}0.68 * * * \\
(0.14)\end{array}$ & $\begin{array}{l}0.51 * * \\
(0.22)\end{array}$ \\
\hline Promoted & $\begin{array}{l}0.05 * * \\
(0.02)\end{array}$ & $\begin{array}{l}0.05^{*} \\
(0.02)\end{array}$ & $\begin{array}{l}0.03 \\
(0.03)\end{array}$ & $\begin{array}{l}0.04 \\
(0.03)\end{array}$ & $\begin{array}{l}0.06^{*} \\
(0.03)\end{array}$ & $\begin{array}{l}0.05 \\
(0.03)\end{array}$ & $\begin{array}{l}0.03 \\
(0.04)\end{array}$ & $\begin{array}{l}0.04 \\
(0.04)\end{array}$ \\
\hline Relegated & $\begin{array}{l}-0.05 * \\
(0.03)\end{array}$ & $\begin{array}{l}-0.04 * * \\
(0.02)\end{array}$ & $\begin{array}{l}-0.03 \\
(0.03)\end{array}$ & $\begin{array}{l}-0.03 \\
(0.02)\end{array}$ & $\begin{array}{l}-0.09 * * \\
(0.04)\end{array}$ & $\begin{array}{l}-0.07 * * \\
(0.03)\end{array}$ & $\begin{array}{l}-0.06 \\
(0.04)\end{array}$ & $\begin{array}{l}-0.06 \\
(0.04)\end{array}$ \\
\hline Relative wage & & & $\begin{array}{l}-0.04 \\
(0.03)\end{array}$ & $\begin{array}{l}-0.03 \\
(0.04)\end{array}$ & & & $\begin{array}{l}-0.08^{*} \\
(0.05)\end{array}$ & $\begin{array}{l}-0.05 \\
(0.06)\end{array}$ \\
\hline Club fixed effects & No & Yes & No & Yes & No & Yes & No & Yes \\
\hline Observations & 4140 & 4140 & 3337 & 3337 & 4140 & 4140 & 3337 & 3337 \\
\hline $\mathrm{R}^{2}$ & 0.007 & 0.007 & 0.007 & 0.005 & 0.007 & 0.006 & 0.008 & 0.005 \\
\hline Number of clubs & & 114 & & 101 & & 114 & & 101 \\
\hline
\end{tabular}

Parameters for the league dummies and constants are not reported; robust standard errors in parentheses; for fixed effects estimates the within $\mathrm{R}^{2}$ is reported; *** $(* *, *)$ indicates that a parameter estimate is significantly different from zero at a $1(5,10) \%$-level

Table 3 shows parameter estimates based on our panel of 114 clubs. The first two columns and columns (5) and (6) show parameter estimates not including the relative wage. Relative attendance has a positive and significant parameter estimate in most of our estimates. Playing on an artificial pitch has a positive and significant effect on home advantage in all our specifications whereby the point estimates are somewhat larger than those of Barnett and Hilditch (1993). Furthermore, being promoted often has a positive effect on home advantage while being relegated has a negative but (sometimes) insignificant effect on home advantage. There are no big differences in parameter estimates between specifications with and without fixed effects. The magnitude of the relative attendance is higher in specifications with club fixed effects. In other words, the within effects of relative attendance on the home advantage are higher than the between effects.

Columns (3), (4), (7) and (8) show parameter estimates if we include the relative wage as one of the explanatory variables. The sign of the relative wage is negative and in only one specification significant at a $10 \%$ level. Including club fixed effects also removes this significance. In further sensitivity analyses, we also investigated the absolute size of the crowd in home matches and away matches and the introduction of a new stadium. None of these variables have a significant effect on relative home advantage.

Our analysis clearly shows that relative home advantage is correlated with attendance. We hesitate to interpret these correlations as causal effects, as it is conceivable that a strong "home reputation" draws more attendance to the stadium. However, since the parameter estimates are identified on within club variation between 


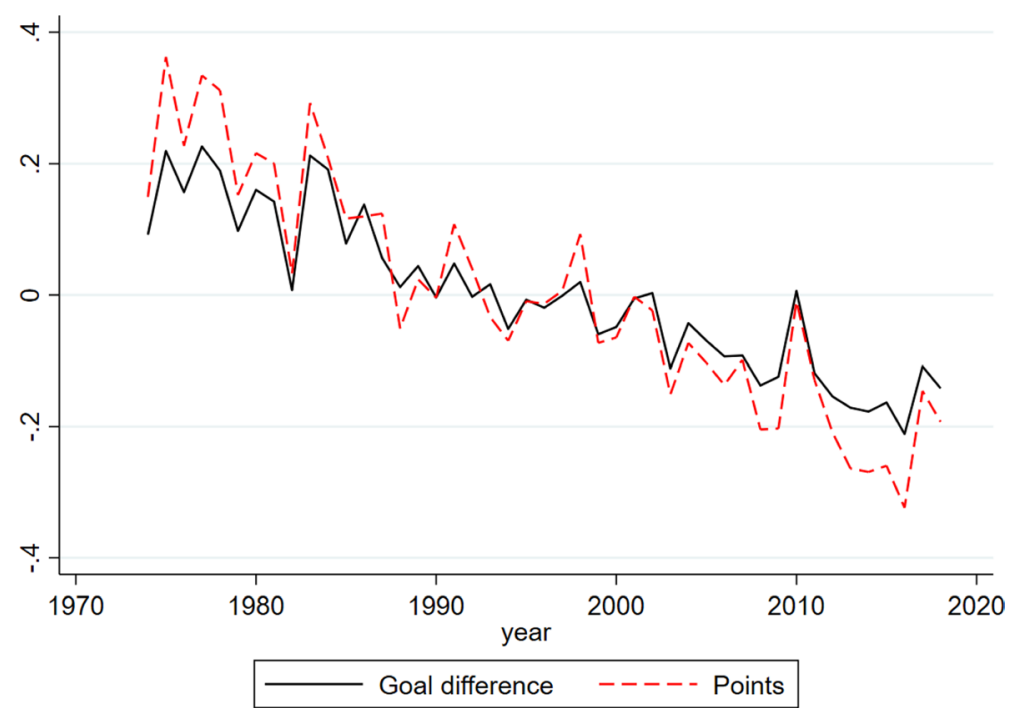

Fig. 4 Calendar year fixed effects home advantage estimates; 1974-2018

seasons reverse causality does not seem very likely. The effect of artificial pitches is economically and statistically significant. We have to point out here that no English club currently plays on artificial turf. Our observations on artificial pitches date back to a time when the quality of these pitches was far lower than today. This may imply we overestimate what the effect would be if a club were to introduce an artificial pitch today. While promotion seems to have a favorable effect, this would be an objective of most clubs in its own right, not just for increasing home advantage. Finally, we note that, taken together, the variables in these regression models explain only a minor portion of the overall variance in home advantage. From a competition point of view the main question is whether clubs are able to exploit their relative home advantage through the factors we examined. Given our reasoning above, the answer is, most likely not.

\subsection{Developments Over Time}

To investigate the development of absolute home advantage over time we estimated Eq. (7), i.e. the determinants of the absolute home advantage. From this, we can isolate the season fixed effects representing the average home advantage. Figure 4 plots the estimated season fixed effects whereby the average over the period of analysis is normalized to zero.

Since the mid 1980s there is clearly a strong downward trend in home advantage that is apart from yearly fluctuations not leveling of in recent year. We can speculate about the causes of this secular decline. It could be that the nature of the home advantage has changed. At the start of our period of analysis players could have been home-grown players i.e. "boys from the neighborhood". At the end of the period of analysis only the stadium was home-based while the players 
Table 4 Parameter estimates team quality

\begin{tabular}{llllll}
\hline Variables & \multicolumn{2}{l}{ Quality goal difference } & & \multicolumn{2}{l}{ Quality points } \\
\cline { 2 - 3 } \cline { 5 - 6 } & $(1)$ & $(2)$ & & $(3)$ & $(4)$ \\
\hline Relative wage & $0.68^{* * *}$ & $0.61 * * *$ & & $0.92 * * *$ & $0.83 * * *$ \\
& $(0.02)$ & $(0.04)$ & & $(0.03)$ & $(0.05)$ \\
Artificial pitch & -0.13 & -0.01 & & -0.19 & 0.04 \\
& $(0.11)$ & $(0.13)$ & & $(0.16)$ & $(0.21)$ \\
Promoted & 0.03 & $0.04 *$ & & 0.04 & 0.05 \\
& $(0.02)$ & $(0.02)$ & & $(0.03)$ & $(0.03)$ \\
Relegated & $-0.11^{* * *}$ & $-0.09 * * *$ & $-0.14 * * *$ & $-0.11^{* * *}$ \\
& $(0.03)$ & $(0.03)$ & & $(0.04)$ & $(0.04)$ \\
Club fixed effects & No & Yes & No & Yes \\
Observations & 3337 & 3337 & 3337 & 3337 \\
$\mathrm{R}^{2}$ & 0.255 & 0.209 & 0.230 & 0.186 \\
Number of clubs & & 101 & & 101 \\
\hline
\end{tabular}

Parameters for the league dummies and constants are not reported; robust standard errors in parentheses; for fixed effects estimates the within $\mathrm{R}^{2}$ is reported; *** (**,*) indicates that a parameter estimate is significantly different from zero at a $1(5,10) \%$-level

were from all corners of the world. In short, less of a home feeling so less of a home advantage. However, one would expect this effect to be larger in the Premier League than in League Two. This is not the case. Nevertheless, one can imagine that improved training methods have had a larger effect on lower division teams while in Premier League teams training methods were already sophisticated for long time. It could be that in matches between better trained players home advantage is less likely to materialize. It is also hard to relate this downward trend to changes in the nature of the game. For example, one might expect that the increase in live game broadcasts in the early nineties caused by the EPL TV contract would lead to better monitoring of refereeing decisions and hence lower home advantage [see e.g., Garicano et al. (2005)]. However, home advantage was already in decline long before TV broadcasting dramatically went up and continued to decline gradually ever since. Likewise, we do not see any jumps for the introduction of the 3-point-for-a-win rule in 1983. Sadly, our data sample ends shortly before the much debated introduction of the Video Assistant Referee (VAR) system.

\subsection{What About Quality?}

As shown in Eq. 6, performance of a team in a particular season is influenced by the relative home advantage but also by the quality of the team. Obviously, clubs that can spend more money should be able to have a better team. To investigate this, we performed similar regressions as for the relative home advantage with one exception, relative attendance is no explanatory variable. Causality is 
likely to work the other way around, i.e. better quality teams attract bigger stadium crowds. Table 4 presents an overview of the relevant parameter estimates.

The effect of the relative wage on the quality of a team is positive and highly significant. Clearly richer clubs are able to attract better players and have better teams. Including club fixed effects hardly influences the parameter estimates. Having an artificial pitch does not affect the quality of the team significantly while in most specifications the effect is negative. In other words, if clubs save money on maintenance by using an artificial pitch rather than maintaining natural grass they do not use these savings to establish a team with a higher quality. Clubs that have been promoted have better quality teams but the effect is significant from zero in only one specification and only at a $10 \%$ level. Clubs that have been relegated have a highly significant lower quality in all specifications. This may have to do with good players leaving the team at the time of relegation.

\section{Conclusions}

The presence of home advantage is well-established in professional sports including football. Previous work has investigated various determinants of this phenomenon ranging from crowd pressure influencing referee decisions and psychological benefits from playing on familiar grounds to fatigue among the away players because of travel distance. Two issues did not receive a lot of research attention. The first issue is whether home advantage is relevant across a season. If every team has the same home advantage then home advantage cancels out in a competition with an equal number of home and away matches. The second issue is whether home advantage is stable over time or whether it has become less relevant over the past decades.

We analyze 45 years of data from English professional football focusing on seasonal home advantage, i.e. the difference in team results between home and away games in terms of points and goal difference over an entire season. Since a club plays the same number of matches at home and away, home advantage is only relevant for the overall performance of a club if it is higher or lower than the average home advantage in its division. We therefore focus on the determinants of this relative home advantage. From an economic point of view this is interesting to study, because it may affect the fairness of the competition. If factors such as the use of artificial pitches or larger stadia deliver a higher relative home advantage, regulators should consider limiting teams' abilities to exploit these advantages.

Our analysis shows that some teams indeed have a persistently higher home advantage than others. Moreover, individual managers have also enjoyed different levels of home advantage over their careers. We find that home advantage correlates with stadium attendance and the use of artificial piches, although the variation in home advantage from year to year is subject to big changes and we can only explain a minor portion of these fluctuations. We also document that there has been a secular decline in home advantage over the past 45 years, i.e. absolute home advantage was substantially larger in the past than it currently is. Since the decline is secular, it does not seem to be related to developments in technology which involve closer monitoring of referee decisions. Finally, we show that the quality of a team is related to the wages paid. This is 
no surprise but in combination with the home advantage findings it does suggest that a higher budget pays a double dividend. A higher budget allows a club to establish a higher quality team and through the increase in the stadium crowd that is related to the higher quality a higher budget is also associated with an increase in home advantage.

Open Access This article is licensed under a Creative Commons Attribution 4.0 International License, which permits use, sharing, adaptation, distribution and reproduction in any medium or format, as long as you give appropriate credit to the original author(s) and the source, provide a link to the Creative Commons licence, and indicate if changes were made. The images or other third party material in this article are included in the article's Creative Commons licence, unless indicated otherwise in a credit line to the material. If material is not included in the article's Creative Commons licence and your intended use is not permitted by statutory regulation or exceeds the permitted use, you will need to obtain permission directly from the copyright holder. To view a copy of this licence, visit http://creativecommons.org/licen ses/by/4.0/.

\section{Appendix: Data and Descriptives}

\begin{tabular}{|c|c|c|c|c|}
\hline Variable & Mean & SD & Definition & Source \\
\hline \multicolumn{5}{|c|}{ Game-level data ( 91,469 observations) } \\
\hline Win & 0.47 & 0.50 & $\begin{array}{l}\text { Dummy }=1 \text { if home team } \\
\text { wins }\end{array}$ & $\begin{array}{l}\text { rsssf.com and football-data. } \\
\text { co.uk }\end{array}$ \\
\hline Draw & 0.27 & 0.45 & $\begin{array}{l}\text { Dummy }=1 \text { if home team } \\
\text { draws }\end{array}$ & \\
\hline Loss & 0.26 & 0.44 & $\begin{array}{l}\text { Dummy }=1 \text { if home team } \\
\text { loses }\end{array}$ & \\
\hline Points & 1.67 & 1.29 & Points obtained by home team & \\
\hline Score & 1.52 & 1.26 & Score of home team & \\
\hline Opponent score & 1.08 & 1.05 & Score of away team & \\
\hline Goal difference & 0.44 & 1.64 & Goal difference for home team & \\
\hline
\end{tabular}




\begin{tabular}{|c|c|c|c|c|}
\hline Variable & Mean & SD & Definition & Source \\
\hline Home adv goaldif & 0.62 & 0.75 & $\begin{array}{l}\text { Seasonal home adv in goal dif } \\
\text { per game }\end{array}$ & \multirow{9}{*}{$\begin{array}{l}\text { Author calculation as described } \\
\text { in section } 2 \text { european-football- } \\
\text { statistics.co.uk, Wikipedia, } \\
\text { and rsssf.com }\end{array}$} \\
\hline Home adv points & 0.44 & 0.49 & $\begin{array}{l}\text { Seasonal home adv in points } \\
\text { per game }\end{array}$ & \\
\hline Ability goaldif & 0.00 & 0.71 & $\begin{array}{l}\text { Seasonal ability in goal dif } \\
\text { per game }\end{array}$ & \\
\hline Ability points & 0.00 & 0.50 & $\begin{array}{l}\text { Seasonal ability in point per } \\
\text { game }\end{array}$ & \\
\hline Raw attendance & 12,752 & 11,813 & $\begin{array}{l}\text { Average attendance per home } \\
\text { game }\end{array}$ & \\
\hline Rel. attendance & -0.09 & 0.41 & $\begin{array}{l}\text { Attendance/seasonal division } \\
\text { average }\end{array}$ & \\
\hline Artificial pitch & 0.01 & 0.07 & $\begin{array}{l}\text { Dummy }=1 \text { if team plays on } \\
\text { artificial turf }\end{array}$ & \\
\hline Promoted & 0.14 & 0.35 & $\begin{array}{l}\text { Dummy }=1 \text { if team promoted } \\
\text { last season }\end{array}$ & \\
\hline Relegated & 0.11 & 0.31 & $\begin{array}{l}\text { Dummy }=1 \text { if team relegated } \\
\text { last season }\end{array}$ & \\
\hline Relative wage $^{a)}$ & -0.08 & 0.39 & $\begin{array}{l}\text { Wage divided by average wage } \\
\text { in the league }\end{array}$ & Companies House \\
\hline Year & 1996 & 13 & Year season ends & \\
\hline Division & 2.55 & 1.10 & Division team plays in & \\
\hline Manager & & & & Peeters et al. (2017) \\
\hline
\end{tabular}

${ }^{a}$ Wage includes taxes and social security payments. This variable has only 3337 observations

\section{References}

Allen, M. S., \& Jones, M. V. (2014). The home advantage over the first 20 seasons of the English Premier League: Effect of shirt colour, team ability and time trends. International Journal of Sport and Exercise Psychology, 12(1), 10-18.

Amez, S., Baert, S., Neyt, B., \& Vandemaele, M. (2020). No evidence for second leg home advantage in recent seasons of European soccer cups. Applied Economics Letters, 27(2), 156-160.

Armatas, V., \& Pollard, R. (2014). Home advantage in Greek football. European Journal of Sport Sciences, 14(2), 116-122.

Attrill, M., Gresty, K., Hill, R., \& Barton, R. (2008). Red shirt colour is associated with long-erm success in English football. Journal of Sports Sciences, 26, 577-582.

Barnett, V., \& Hilditch, S. (1993). The effect of an artificial pitch surface on home team performance in football (soccer). Journal of the Royal Statistical Society: Series A (Statistics in Society), 156(1), 39-50.

Boyko, R., Boyko, A., \& Boyko, M. (2010). Referee bias contributes to home advantage in English premiership football. Journal of Sports Sciences, 25(11), 1185-1194.

Bray, S., Law, J., \& Foyle, J. (2003). Team quality and game location effects in English professional soccer. Journal of Sport Behavior, 26, 319-334.

Buraimo, B., Forrest, D., \& Simmons, R. (2010). The 12th man? Refereeing bias in English and German soccer. Journal of the Royal Statistical Society: Series A (Statistics in Society), 173(2), 431-449.

Carmichael, F., \& Thomas, D. (2005). Home-field effect and team performance: Evidence from English professional football. Journal of Sports Economics, 6(3), 264-281.

Clarke, S. R., \& Norman, J. M. (1995). Home ground advantage of individual clubs in English soccer. The Statistician, 44(4), 509-521. 
Dawson, P., Dobson, S., Goddard, J., \& Wilson, J. (2007). Are football referees really biased and inconsistent? Evidence on the incidence of disciplinary sanction in the English Premier League. Journal of the Royal Statistical Society: Series A (Statistics in Society), 170, 231-250.

Garicano, L., Palacios-Huerta, I., \& Prendergast, C. (2005). Favoritism under social pressure. Review of Economics and Statistics, 87(2), 208-216.

Goller, D., \& Krumer, A. (2020). Let's meet as usual: Do games played on non-frequent days differ? Evidence from top European soccer leagues. European Journal of Operational Research, 286, $740-754$.

Johnston, R. (2008). On referee bias, crowd size and home advantage in English soccer Premiership. Journal of Sports Sciences, 26, 563-568.

Krumer, A. (2020). Testing the effect of kick-off time in the UEFA Europa League. European Sport Management Quarterly, 20(2), 225-238.

Krumer, A., \& Lechner, M. (2018). Midweek effect on soccer performance: Evidence from the German Bundesliga. Economic Inquiry, 56(1), 193-207.

Peeters, T., Szymanski, S., \& Terviö, M. (2017). The inefficient advantage of experience in the market for football managers. Tinbergen Institute Discussion Paper (pp. 2017-2116).

Pollard, R. (1986). Home advantage in soccer: A retrospective analysis. Journal of Sports Sciences, 4(3), 237-248.

Pollard, R., \& Armatas, V. (2017). Factors affecting home advantage in football World Cup qualification. International Journal of Performance Analysis in Sport, 17(1-2), 121-135.

Ponzo, M., \& Scoppa, V. (2018). Does the home advantage depend on crowd support? Evidence from same-stadium derbies. Journal of Sports Economics, 19(4), 562-582.

Van Damme, N., \& Baert, S. (2019). Home advantage in European international soccer: Which dimension of distance matters? Economics: The open-access. Open-Assessment E-Journal, 13(50), 1-17.

Van Ours, J. C. (2019). A note on artificial pitches and home advantage in Dutch professional football. De Economist, 167, 89-103.

Publisher's Note Springer Nature remains neutral with regard to jurisdictional claims in published maps and institutional affiliations. 


\section{University Library}

\section{- M M I E R R V A gateway to Melbourne's research publications}

Minerva Access is the Institutional Repository of The University of Melbourne

Author/s:

Peeters, T;van Ours, JC

Title:

Seasonal Home Advantage in English Professional Football; 1974-2018

Date:

2021-01-01

Citation:

Peeters, T. \& van Ours, J. C. (2021). Seasonal Home Advantage in English Professional Football; 1974-2018. De Economist, 169 (1), pp.107-126. https://doi.org/10.1007/ s10645-020-09372-z.

Persistent Link:

http://hdl.handle.net/11343/252178

License:

cc-by 